\title{
Refractory Crohn's Disease of External Genitalia in a Female Successfully Treated with Adalimumab
}

\author{
Shivi Nijhawan ${ }^{1}$, Manisha Nijhawan², Savita Agarwal ${ }^{3}$, Pallavi Goel ${ }^{4}$, Sinni Jain ${ }^{5}$, Anand Sharma ${ }^{6}$, Ankit Meherda ${ }^{7}$
}

\begin{abstract}
Crohn's disease (CD) is a chronic inflammatory bowel disease with granulomas and ulcers in the bowel. Cutaneous lesions may occur as a totally separate entity without involvement of gastrointestinal (Gl) tract, in which case it is termed as metastatic Crohn's disease. Gynecologic involvement is infrequent and difficult to diagnose. A 23-year-old female presented to us with complaints of vulvar swelling and multiple, oval to linear, typical knife cutting deep ulcers on the perineal folds since 6 years. We performed a biopsy, which showed follicular plugging with epitheloid cell granuloma in subcutis and foci of chronic inflammation. The list of differential diagnosis included cutaneous tuberculosis, sarcoidosis, deep fungal infection, lymphogranuloma venerum (LGV), and Crohn's disease of vulva. Clinical correlation with investigations leads to a diagnosis of Crohn's disease of vulva by exclusion. Patient was earlier treated with oral steroids, antibiotics, and immunosuppressants like azathioprine but showed only mild improvement. In view of previous nonresponse, the condition was regarded as a refractory one. We thus planned biological therapy in the form of adalimumab. The patient showed a significant improvement in ulcers.

Keywords: Crohn's disease, Granuloma, Vulva.

Journal of Mahatma Gandhi University of Medical Sciences \& Technology (2018): 10.5005/.jp-journals-10057-0088
\end{abstract}

\section{INTRODUCTION}

Crohn's disease (CD) is a chronic inflammatory bowel disease of unknown pathogenesis in which there is a development of granulomas and ulcers in the bowel. It can involve any section of the bowel, terminal ileum being the most common. Cutaneous lesions may parallel gastrointestinal (Gl) disease activity or may occur as a totally separate entity in which case it is called as metastatic Crohn's disease. Gynecologic involvement is infrequent, diverse, and often difficult to diagnose. Vulvar involvement due to Crohn's disease is an extremely rare condition with only a few reported cases. ${ }^{1}$ Till now, only about 130 cases have been reported in the literature.

\section{Case Description}

A 23-year-old married female presented to our outpatient department with complaints of swelling of vulva since 7 years. The swelling started in 2010 during 3 months of gestation which was gradually progressive $(1-5 \mathrm{~cm})$. She underwent emergency lower segment cesarian section (LSCS) in July 2010. Excision of the swelling was done in January 2011. Few weeks later, the swelling started growing again and progressed to involve perineum and gluteal region. A few painful ulcers also developed on both genitocrural folds and the inner aspect of thighs (Fig. 1).

There was no history of vaginal discharge or abnormal vaginal bleeding. There was no history of fever, anorexia, weight loss, chronic cough, hemoptysis, or breathlessness. History of nausea, vomiting, abdominal pain, diarrhea, blood in stool, or oral ulcers was also absent. Premarital or extramarital sexual contact in patient and her partner was also ruled out.

General and systemic examination was normal. On local examination, a firm, nontender, asymmetric lobulated mass of size around $15 \times 8 \mathrm{~cm}$, arising from vulva extending to the perineum and gluteal region was seen. Along with this, multiple, tender, oval to linear, deep "knife cutting" ulcers with well-demarcated margins of size varying from $0.5 \mathrm{~cm}$ to $5 \mathrm{~cm}$ with mucopurulent discharge were seen. \begin{tabular}{l}
\hline \hline${ }^{1-7}$ Department of Dermatology, Mahatma Gandhi Medical College \\
and Hospital, Mahatma Gandhi University of Medical Sciences and \\
Technology, Jaipur, Rajasthan, India \\
Corresponding Author: Shivi Nijhawan, Department of Dermatology, \\
Mahatma Gandhi Medical College and Hospital, Mahatma Gandhi \\
University of Medical Sciences and Technology, Jaipur, Rajasthan, \\
India, Phone: +91 9928068867, e-mail: shivi.nijhawan@yahoo.com \\
How to cite this article: Nijhawan S, Nijhawan M, Agarwal S, et al. \\
Refractory Crohn's Disease of External Genitalia in a Female \\
Successfully Treated with Adalimumab. J Mahatma Gandhi Univ Med \\
Sci Tech 2018;3(3):105-107. \\
Source of support: Nil \\
Conflict of interest: None
\end{tabular}

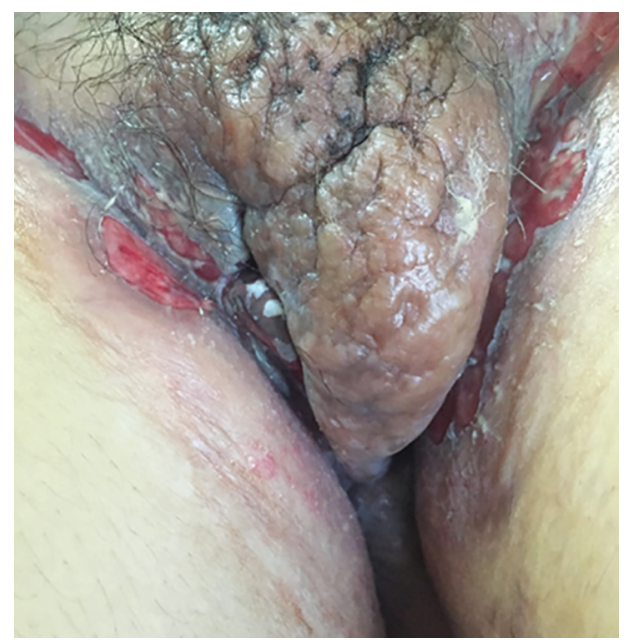

Fig. 1: Swelling rising from vulva, asymmetric, firm lobulated swelling. Multiple, oval to linear, typical knife cutting deep ulcers with welldemarcated margins of size varying from 0.5 to $5 \mathrm{~cm}$

(c) The Author(s). 2018 Open Access This article is distributed under the terms of the Creative Commons Attribution 4.0 International License (https://creativecommons. org/licenses/by-nc/4.0/), which permits unrestricted use, distribution, and non-commercial reproduction in any medium, provided you give appropriate credit to the original author(s) and the source, provide a link to the Creative Commons license, and indicate if changes were made. The Creative Commons Public Domain Dedication waiver (http://creativecommons.org/publicdomain/zero/1.0/) applies to the data made available in this article, unless otherwise stated. 

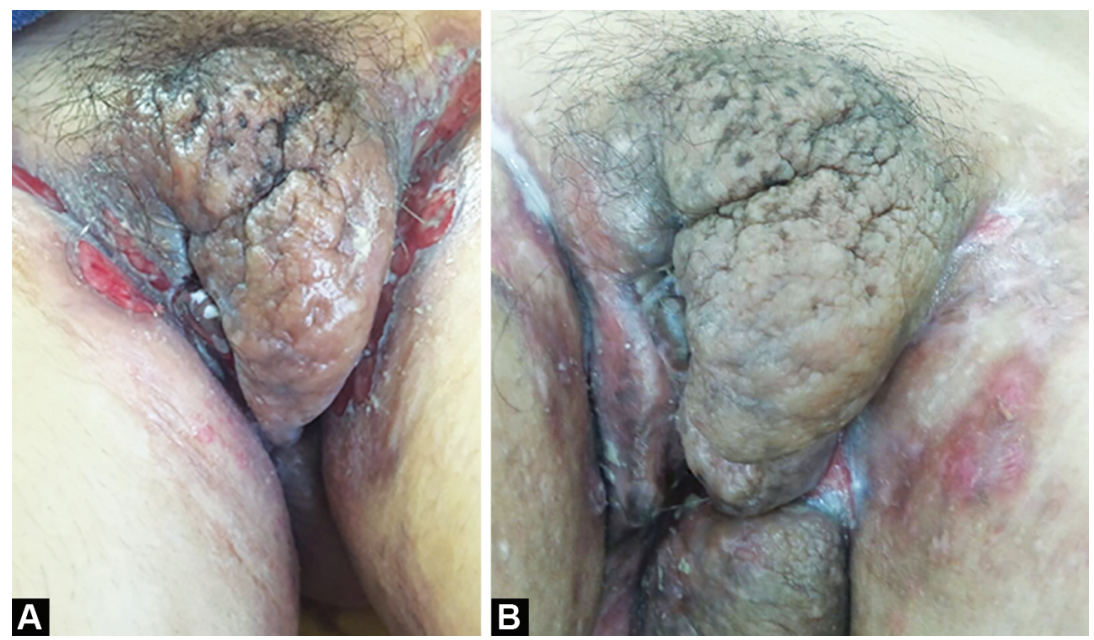

Figs $2 A$ and B: Significant healed ulcers after five cycles of adalimumab

Per vaginal and per rectal examination was normal. Palms, soles, and scalp examination was normal. On the basis of history and clinical examination, a list of differential diagnosis was made, which included tertiary stage of lymphogranuloma venerum (LGV), cutaneous tuberculosis, deep fungal infection, sarcoidosis, filariasis, and vulval Crohn's disease.

The routine hematologic workup was normal except for a raised erythrocyte sedimentation rate (ESR) of $42 \mathrm{~mm}$. Venereal disease research laboratory (VDRL), enzyme-linked immunosorbent assay for human immunodeficiency virus, and $\mathrm{HBsAg}$ were nonreactive. Angiotensin-converting enzyme levels for sarcoidosis were normal, tissue fungal culture (including atypical mycobacteria). Polymerase chain reaction for tuberculosis and LGV were negative. Night blood sample for microfilaria was also negative.

Mantoux test and chest $\mathrm{X}$-ray were normal. Magnetic resonance imaging of pelvis showed vulvar edema with soft tissue thickening within superficial subcutaneous layer extending up to the perineum. A sinus tract was also seen extending from right vulval region to right gluteal region.

A biopsy of the swelling was done which showed follicular plugging with epitheloid cell granuloma in subcutis and foci of chronic inflammation comprising a significant number of plasma cells and few lymphocytes. Special stains for acid fast bacilli (AFB) and reticulin were noncontributory.

Gastrointestinal biopsy was done from terminal ileum which showed only mild inflammatory changes without any features of granulomatous disease. Colonoscopy was normal. Anti-Saccharomyces cerevisiae antibodies (ASCA) was negative. In view of the clinical and histopathological features and all other investigations, a diagnosis of Crohn's disease of external genitalia was made by exclusion.

In view of the previous nonresponse, the condition was regarded as a refractory one. We planned for a biological therapy in the form of injection adalimumab (exemptia; Zydus). Starting dose was $160 \mu \mathrm{g}$ followed by $80 \mu \mathrm{g}, 40 \mu \mathrm{g} \mathrm{s} / \mathrm{c}$ at an interval of 2 weeks. A maintenance dose of $40 \mathrm{mg}$ was given for 2 months.

There was a significant healing of the ulcers after five cycles of adalimumab (Fig. 2).

\section{Discussion}

Cutaneous manifestations occur in 22-44\% of patients with Crohn's disease. ${ }^{2}$ Three distinct patterns of cutaneous involvement are seen in Crohn's disease. A direct extension from the bowel to perineal skin, stomal sites, or lips is the commonest cutaneous presentation. The second pattern includes extraintestinal cutaneous conditions associated with Crohn's disease, such as pyoderma gangrenosum, erythema nodosum, and erythema multiforme. ${ }^{3}$ The third pattern is metastatic or isolated Crohn's disease arising at sites discontinuous from the GI tract. The exact pathogenesis of metastatic $C D$ is unknown, although it has been proposed that a T lymphocytemediated type IV reaction could be partially responsible. ${ }^{4}$ The disease was first described by Parks et al., ${ }^{5}$ It can present as cutaneous ulcerations, plaques, papules or nodules over skin folds, the inframammary area, limbs, penis, vulva, trunk, or face. ${ }^{6}$ Cutaneous lesions are usually in the inguinal and perineal areas, because they are areas of increased moisture. ${ }^{7}$ A retrospective review by Ploysangam et al. of 80 cases of metastatic $C D$ demonstrated that $56 \%$ of women had gynecological involvement. ${ }^{8}$

As such there is no definite curative treatment for metastatic Crohn's disease. Many treatment modalities have been tried, such as topical, intralesional, systemic steroids, sulfasalazine, mesalamine, oral metronidazole, hyperbaric oxygen, ${ }^{9}$ and antitumor necrosis factor-a antibodies (Infliximab)..$^{10}$ Adalimumab is found to be effective in achieving short-term and long-term remission and complete fistula healing in CD. ${ }^{11}$ Now we have considered it to be used in this case. There are reports of successful use of adalimumab in treating metastatic Crohn'sdisease. ${ }^{12}$ Advanced cases may require vulvectomy. Werlin et al. have reported that vulvar ulcers may precede intestinal manifestations by up to 18 years. ${ }^{13}$ Therefore, chronic vulvar ulcers require a thorough long-term follow-up. A differential diagnosis of metastatic Crohn's disease should be kept in mind in a patient presenting with a vulvar swelling and multiple nonhealing ulcers over the perineum. In a refractory case like this, a purely human-derived biologic like adalimumab can give promising results.

\section{References}

1. Kingsland CR, Alderman B. Crohn's disease of the vulva. J R Soc Med 1991;84(11):693. DOI: 10.1177/014107689108400418. 
2. Goyal A, Mansel RE, Young HL, et al. Metastatic cutaneous Crohn's disease of the nipple: report of a case. Dis Colon Rectum 2006;49(1):132-134. DOI: 10.1007/s10350-005-0218-2.

3. Leu S, Sun PK, Collyer J, et al. Clinical spectrum of vulva metastatic crohn's disease. Dig Dis Sci 2009;54(7):1565-1571. DOI: 10.1007/ s10620-008-0448-y.

4. Shum DT, Guenther L. Metastatic crohn's disease case report and review of the literature. Arch Dermatol 1990;126(5):645-648. DOI: 10.1001/archderm.1990.01670290089015.

5. Parks AG, Morson BC, Pegum JS. Crohn's disease with cutaneous involvement. Proc R Soc Med 1965;58(4):241-242. DOI: 10.1177/003591576505800419.

6. Sangueza OP, Davis LS, Gourdin FW. Metastatic Crohn's disease. South Med J 1997;90(9):897-900. DOI: 10.1097/00007611-199709000-00006.

7. Guest GD, Fink RL. Metastatic Crohn's disease: case report of an unusual variant and review of the literature. Dis Colon Rectum 2000;43(12):1764-1766. DOI: 10.1007/bf02236866.

8. Ploysangam T, Heubi JE, Eisen D, et al. Cutaneous Crohn's disease in children. J Am AcadDermatol 1997;36(5 Pt 1):697-704. DOI: 10.1016/ s0190-9622(97)80320-9.
9. Brady CE3rd, Cooley BJ, Davis JC. Healing of severe perineal and cutaneous Crohn's disease with hyperbaric oxygen. Gastroenterology 1989;97(3):756-760. DOI: 10.1016/0016-5085(89) 90649-5.

10. Van Dullemen HM, de Jong E, Slors F, et al. Treatment of therapyresistant perineal metastatic Crohn's disease after proctectomy using anti-tumor necrosis factor chimeric monoclonal antibody, CA2: report of two cases. Dis Colon Rectum 1998;41(1):98-102. DOI: 10.1007/bf02236903.

11. Song $\mathrm{YN}$, Zheng $\mathrm{P}$, Xiao $\mathrm{JH}$, et al. Efficacy and safety of adalimumab for the Crohn's disease: a systematic review and meta-analysis of published randomized placebo-controlled trials. Eur J Clin Pharmacol 2014;70(8):907-914. DOI: 10.1007/s00228-014-1702-1.

12. Miller FA, Jones CR, Clarke LE, et al. Successful use of adalimumab in treating cutaneous metastatic Crohn's disease: report of a case. Inflamm Bowel Dis 2009;15(11):1611-1612. DOI: 10.1002/ibd. 20853.

13. Werlin SL, Easterly NB, Oechler H. Crohn's disease presenting as unilateral labial hypertrophy. J Am Acad Dermatol 1992;27(5 Pt 2): 893-895. DOI: 10.1016/0190-9622(92)70276-I. 